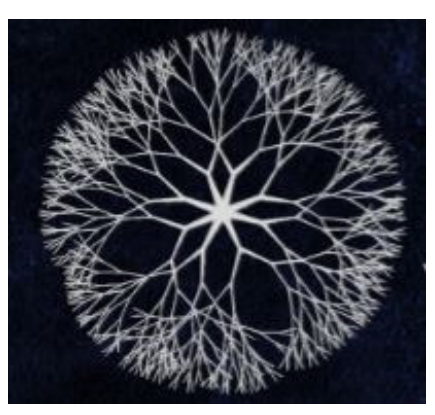

Dossiê - Simpósio USP "Construindo diálogos interdisciplinares"

\title{
Embalsamamentos no século XIX: segredos, técnicas e polêmicas
}

\author{
Nanci Leonzo \\ Profa. Livre Docente - USP/FFLCH - História Social \\ nleonzo@usp.br
}

\author{
Maria José Saenz S. P. de Almeida \\ Doutoranda em História Social - FFLCH - USP \\ mariajsurita@gmail.com
}

Recebido em 29/01/2018. Aprovado em 05/04/2018.

Como citar este artigo: Leonzo, N.; ALMEIDA, M.J.S.S.P. "Embalsamamentos no século XIX: segredos, técnicas e polêmicas". Khronos, Revista de História da Ciência, nº5, pp. 47 - 57. 2018.

Disponível em <http://revistas.usp.br/khronos >. Acesso em dd/mm/aaaa.

Resumo: No limiar entre ciência e arte, os embalsamamentos durante o século XIX, antes da utilização do formol, envolveram médicos do Brasil e da França em uma série de controvérsias que revelam muito sobre a cultura fúnebre do Oitocentos. Neste estudo de caso, acompanhamos a trajetória de José Tavano, português que chegou ao Brasil em meados de 1858 disposto a trabalhar como médico, cirurgião e, principalmente, embalsamador, utilizando o sistema desenvolvido por um conhecido químico francês do qual era cessionário. Suas prováveis relações com pessoas influentes no Império e a troca de artigos com um desafeto são elementos que ajudam a compor o cenário da chamada medicina científica da época.

Palavras-chave: ciência, história, embalsamamento.

\section{Embalming in the $1^{\text {th }}$ century: secrets, techniques and controversy}

\begin{abstract}
On the threshold between science and art, the funeral embalming during the 19th century, before the use of formalin, involved physicians from Brazil and France in a number of controversial issues which reveal a great deal about the eighteen hundreds' funeral culture. In this case study we followed José Tavano's life, a Portuguese who came to Brazil in 1858, willing to work as a physician, surgeon and mainly embalmer, using the system developed by a wellknown French chemist, of whom he was cessionary. His probable relationships with influent people in Imperial Brazil and the exchange of articles with a foe are elements helping to make up the backdrop of the so-called scientific medicine of that time.
\end{abstract}

Keywords: embalming, science history, medicine history. 


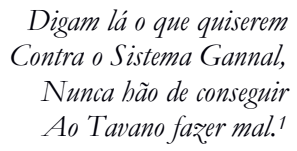

Um indivíduo identificado apenas como Vasseur, preparador de anatomia, redigiu, no século XIX, uma correspondência dirigida a um certo Dr. Vignollo, na qual lamentou alguns dissabores vividos por aqueles que se dedicavam ao ofício de embalsamar cadáveres - eventualidade que "de tão rara poderia nem aparecer na carreira de um médico". Um dos problemas por ele apontado foi a falta de corporativismo, em decorrência de a arte ter nascido fora do ensinamento oficial e ser por muito tempo domínio de raros inovadores. Em defesa do aprimoramento da técnica, Vasseur cobrou de seus pares mais esforços, inclusive para a formação de conselhos autorizados. Por fim, conclamou todos a se unirem pelo respeito soberano às famílias. Nesta última observação, aliás, o discurso do anatomista fazia coro com outros de sua época, inclusive com o polêmico químico e farmacêutico francês Jean-Nicolas Gannal (1791-1852) já falecido, no momento defendido por um de seus filhos, o médico e farmacêutico de primeira classe, Felix Gannal (1829-1905), também embalsamador².

Muitos atribuem a Gannal a criação do sistema de embalsamamento com injeção na artéria carótida. Sua técnica e seu líquido embalsamador, cuja fórmula durante muito tempo foi mantida em segredo ${ }^{3}$, disseminaram-se por diversos países, sendo exportados em tonéis e garrafões para seus cessionários. Entre estes havia um médico português, formado, ao que tudo indica, na Bélgica, chamado José Tavano (?-1894). Não conseguimos apurar a razão pela qual ele se interessou por exercer tal atividade no Brasil. Contudo, identificamos que, em 24 de maio de 1858, ele enviou de Flessinger, importante porto comercial situado na ilha de Walcheren, localizada na então província holandesa da Zelândia, uma carta ao brasileiro Antonio Gonçalves Dias (1823-1864), o qual se encontrava na Europa em missão especial de estudos e pesquisas, sobre questões relacionadas com a sobrevivência na capital do Império brasileiro e, talvez, a respeito das possibilidades do exercício da medicina ${ }^{4}$. Não há dúvida de que eles se conheceram em algum lugar do velho continente e que, provavelmente, o literato, morto em um naufrágio ocorrido nas costas do Maranhão, durante uma viagem da França ao Brasil, lhe deu algumas informações básicas sobre o país. Ao emigrar para o Brasil, Tavano viajou a bordo de um navio que partiu de Antuérpia e durante a longa travessia cuidou dos tripulantes doentes ${ }^{5}$. Desembarcou para tentar

1 O BRAZ. "Novo Braz". A Formiga. Rio de Janeiro, edição 3, fevereiro 1862. p. 4.

2 A carta de Vausser e a resposta de Gannal podem ser consultadas em: GANNAL, Félix. Reponse de M. le Dr. Gannal a la lettre adressée par M. Vassseur, Préparateur d'Anatomie et Fournisseur de la Faculté de Médecine, à M. Le Dr. Vignollo, à l'occasion de l'embaumement de Mgr l'arquevêque de Paris. Paris: Rignoux, Imprimeur de la Faculté de Médecine, 1863. Disponível em: <http://gallica.bnf.fr/ark:/12148/bpt6k56255750>. Acesso em: 11 de maio de 2018.

${ }^{3}$ Desenvolvidas por diferentes médicos, químicos e farmacêuticos, as fórmulas usadas no embalsamamento durante o século XIX antecederam ao emprego do formol, cujo uso na conservação dos cadáveres para o estudo da anatomia deu-se a partir do final do mesmo século, tanto nas instituições europeias quanto no Brasil. Na Faculdade de Medicina do Rio de Janeiro, o uso do formol teve início em 1897 por iniciativa do médico Augusto Brant Paes Leme (1862-1943). Ver: CARVALHO, Bulhões. Boletim da semana. A conservação dos cadáveres para os estudos anatômicos. In: O Brazil-Medico: revista semanal de medicina e cirurgia. Rio de Janeiro: Policlínica Geral do Rio de Janeiro, v. 13, n.15, 15 de abril de 1899. pp.145-146. Disponível em: <https://www.obrasraras.fiocruz.br/media.details.php?mediaID=124>. Acesso em: 11 de maio de 2018.

${ }^{4}$ Carta de José Tavano a Antonio Gonçalves Dias sobre pagamento de aluguéis de casa e outros assuntos. Anais da Biblioteca Nacional. Rio de Janeiro, RJ. A. G. Dias. Catálogo de Manuscritos e Bibliografia. I$5,2,34$.

${ }^{5}$ Jornal do Comércio. Rio de Janeiro, edição 207, 26 de julho de 1858, p. 2. 
a vida, de início, como médico e cirurgião, em 26 de julho de 1858, apresentando-se como especialista no tratamento de doenças venéreas e uma espécie de discípulo de dois prestigiados sifilógrafos franceses, sendo um deles Philippe Ricord (1880-1889) ${ }^{6}$.

Há indícios de que Tavano logo entrou em contato com os principais jornais locais, sob a indicação de Antonio Gonçalves Dias, muito prestigiado sobretudo pela sua obra literária. É provável que tenha tentado obter a licença para exercer sua profissão na Faculdade de Medicina do Rio de Janeiro, porém, não tendo êxito, se dirigiu, de imediato, à da Bahia. Levantamos a hipótese de que o auxílio teria vindo, por sugestão do autor de Canção do Exílio, de uma tradicional família baiana, isto é, Muniz Barreto, radicada na capital do Império. Um de seus membros era Joaquim Francisco Alves Branco Muniz Barreto (1800-1885), proprietário, desde 1853, do Correio Mercantil, Instrutivo, Político e Universal, Rio de Janeiro ${ }^{7}$. Tavano prestou exames de suficiência na instituição localizada em Salvador, obtendo o reconhecimento de seu diploma em fins de $1858^{8}$, atendendo, assim, às exigências impostas aos médicos estrangeiros que pretendiam se dedicar à medicina em território brasileiro.

O Correio Mercantil muito colaborou para o sucesso de Tavano. Após meados de 1858, portanto, logo depois de sua chegada ao Brasil, quando o advogado, jornalista e então deputado geral da província do Rio de Janeiro pelo Partido Liberal Francisco Otaviano de Almeida Rosa (1826-1889), nascido na mesma cidade e amigo de Gonçalves Dias, se associou, no referido periódico, a Muniz Barreto e filhos.

Otaviano, como ficou conhecido, tinha experiência no ramo, pois atuara em outros jornais locais, inclusive no Jornal do Comércio $^{9}$, onde Tavano fez seus primeiros anúncios propagandistas. Era filho do médico Otaviano Maria da Rosa que presidiu, em 1831, a Sociedade de Medicina do Rio de Janeiro e, também, cinco anos depois, a Academia Imperial de Medicina ${ }^{10}$, instituições fundadas, respectivamente, em 1829 e 1835. Ele não era bem-visto por parte do corpo médico de sua cidade natal em razão de seu comportamento após a formatura na Faculdade de Direito de São Paulo. Com a morte repentina e precoce de seu pai, motivada por uma "febre", em 29 de janeiro de 1842, Otaviano correu o risco de ser obrigado a abandonar o curso jurídico por falta de recursos para sua manutenção fora do domicílio familiar. Diante da inesperada situação, vários amigos do falecido auxiliaram financeiramente, mediante subscrições, a viúva, mãe de três filhos, comprometendo-se, inclusive, alguns de seus pares da Academia Imperial de Medicina a mantê-lo estudando em São Paulo, contribuindo com uma quota mensal depositada em uma espécie de conta ${ }^{11}$. Contudo, ele nunca teria entrado em contato com seus beneficiários após sua formatura em 1845. Em sessão geral extraordinária de 4 de junho do ano seguinte, o Presidente Joaquim Cândido Soares de Meirelles (1797-1868) solicitou que o Secretário registrasse em ata tal fato, o que gerou uma violenta discussão, passando, enfim, o saldo da referida conta para os cofres da instituição ${ }^{12}$. O apoio incondicional de Otaviano, que se tornou

${ }^{6}$ Idem, edição 355, 23 de dezembro 1859, p. 4.

${ }^{7}$ Correio Mercantil, Instrutivo, Político e Universal. Rio de Janeiro: edição 83, 24 de março 1853, p. 1. Disponível em: <http://memoria.bn.br/pdf/217280/per217280_1848_00083.pdf>. Acesso em: 11 de maio de 2018.

Daqui em diante apenas citado como Correio Mercantil.

${ }^{8}$ Levantamento nominal dos formandos de 1812 a 2008 da Faculdade de Medicina da Bahia - UFBA. Disponível em: <http://www.fameb.ufba.br/dmdocuments/formadosfmb1812a2007.pdf>. Acesso em: 11 de maio de 2018.

${ }^{9}$ Como fonte de informações, foi consultado o perfil de Francisco Otaviano apresentado no site da Academia Brasileira de Letras. Disponível em: < http://www.academia.org.br/academicos/francisco-otaviano $>$. Acesso em: 11 de maio de 2018.

10 Semanário de Saúde Pública, RJ, edição 21, 21 maio 1831, p. 116. Jornal do Comércio, RJ, edição 100, 6 de maio 1836, p. 3.

11 Revista Médica Brasileira, edição 1, maio de 1842. p. 41.

12 Anais de Medicina Brasiliense, ano 2, vol. 2, 11 de abril 1847, p. 241 e 242. 
um hábil político e chegou a ocupar o cargo de Senador, a um profissional estrangeiro, no caso Tavano, teria agravado o impasse causado pela ingratidão. A competição era uma realidade na área médica fluminense e tornava-se necessário enfrentá-la com inovações, concluiu, por sua vez, diante das circunstâncias, o médico português interessado em alcançar prestígio e riqueza, o que se concretizou nas décadas de 1860 a 1880, apesar de alguns percalços.

Um dos principais beneficiários do estudante Otaviano foi o Dr. José Mauricio Nunes Garcia (1808-1884), colega e amigo de seu pai ${ }^{13}$. De acordo com Lycurgo Santos Filho, este professor de anatomia da Faculdade de Medicina do Rio de Janeiro teria sido, na década de 1840, o introdutor do método de Gannal para a conservação dos cadáveres, ainda que com o objetivo de aperfeiçoar seus estudos sobre a matéria ${ }^{14}$. Ao obter a certeza de que os embalsamamentos ainda não haviam sido, no Brasil, devidamente explorados do ponto de vista comercial, Tavano aqui permaneceu poucos dias. Embarcou para a Europa a fim de cuidar de questões pessoais e, principalmente, com o propósito de estagiar com Félix Gannal. Desejava se tornar seu cessionário exclusivo no Império brasileiro. O êxito dessa iniciativa foi comprovado por um certificado de 2 de outubro de 1859, no qual o herdeiro de Jean-Nicolas Gannal atestou que o médico português havia embalsamado em sua presença e sob sua direção diversas pessoas ${ }^{15}$.

Logo após seu retorno ao Rio de Janeiro, em dezembro do mesmo ano, passou a atender os pacientes em sua própria residência, situada na rua da Alfândega, 31, reservando data e horário aos doentes pobres e doando-lhes remédios, como era habitual entre os médicos oitocentistas brasileiros. Atuou como cirurgião dotado para extirpar pólipos e tumores, além de médico capaz de curar diversas doenças graves. Tais atividades, exercidas durante as décadas seguintes e em diferentes momentos, no Hospital da Beneficência Portuguesa, em seu domicílio particular e na sua própria Casa de Saúde, o consagraram até sua retirada definitiva do Brasil pouco antes de seu falecimento, em agosto de 1894, na cidade de Lisboa ${ }^{16}$. Uma interessante prova do prestígio profissional alcançado é, por exemplo, um anúncio de 1887, no qual atesta a eficácia da Emulsão de Scott, preparado oriundo dos Estados Unidos e apresentado, ao tempo, como um composto de óleo puro de fígado de bacalhau e hipofosfitos de cal e soda ${ }^{17}$. Cabe ressaltar que, talvez com o crescente envolvimento do amigo Otaviano na política imperial, Tavano se aproximou da nobreza, ingressando, inclusive, em 1867, na Sociedade Portuguesa Amor à Monarquia, da qual se tornou presidente. Chegou a ter como parceiro, em uma operação de aneurisma na virilha do lado direito de um paciente, Vicente Cândido Figueira de Saboia, Barão e Visconde de Sabia (18361909), ao tempo presidente da Faculdade de Medicina do Rio de Janeiro e médico de confiança da casa imperial ${ }^{18}$. A trajetória de Tavano, com vistas à elevação social e ao reconhecimento profissional, confirma as observações de Ilmar Rohloff de Mattos, o qual, ao analisar o papel da alta burocracia imperial e dos agentes não públicos na manutenção do status quo, considerou os médicos, jornalistas e literatos como parte integrante de um conjunto unificado interessado na manutenção da ordem, como se fossem "peças estratégicas no jogo da constituição do Estado Imperial e da classe senhorial"19.

${ }^{13}$ Jornal do Comércio, RJ, edição 78, 21 de março 1844, p. 2.

${ }^{14}$ SANTOS FILHO, Lycurgo. História Geral da Medicina Brasileira. São Paulo: EDUSC; Hucitec, 1991. Vol. 2, p. 535.

15 Correio Mercantil, RJ, edição 214, 8 de agosto de. 1858, p. 1 e edição 106, 17 de abril 1860, p. 2.

${ }_{16}$ Correio Mercantil, RJ, edição 63, 4 de março de 1860, p.2 e edição 82, 23 de março de 1860, p.2. Jornal do Comércio, RJ, edição 203, 23 de julho de 1882, p. 3 e edição 209, 29 de julho de 1883, p. 3. Gazeta de Notícias, RJ, edição 10, 10 de janeiro de 1885, p. 3 e edição 227, 15 de agosto de 1886, p. 3. O País, RJ, edição 4427, 21 de setembro de 1894, p. 5.

17 O Fluminense, RJ, edição 1369, 6 de março 1887. p. 3.

18 Diário do Rio de Janeiro, RJ, edição 105, 30 de abril 1867, p. 2. O País, RJ, edição 330, 28 de novembro de 1886, p. 2. SANTOS FILHO, Lycurgo. Op. cit., vol. 2, pp. 133;136.

${ }^{19}$ MATTOS, Ilmar Rohloff. O tempo Saquarema. São Paulo: Hucitec, 1987. p. 212 e 213. 
Enquanto atuou como embalsamador, Tavano, como vimos, jamais deixou de atender em outras áreas da medicina, confirmando a premissa de que o embalsamamento era uma "eventualidade rara na vida de um médico". Nos primeiros meses de 1860, passou a divulgar, além de suas atividades como médico e cirurgião, a condição de cessionário de Gannal no Brasil. Tudo indica que realizou seu primeiro serviço em agosto do mesmo ano, no cadáver de um homem falecido de ataque apoplético ${ }^{20}$, o jornalista Manoel Moreira de Castro. Durante o enterramento, Otaviano esteve presente, conduzindo o féretro e proferindo discurso ${ }^{21}$. Poucos dias depois desse episódio, ao ler o jornal Correio Mercantil, o profissional português deve ter percebido a dimensão dos problemas que enfrentaria caso continuasse embalsamando cadáveres pelo sistema francês. Uma notícia intitulada O cessionário do sistema Gannal, dirigida ao público em geral e em especial ao governo, trazia o trecho de um relatório apresentado à Academia Imperial de Medicina de Paris com graves acusações ao método de embalsamamento de Gannal em detrimento do sistema desenvolvido por outro cientista, o médico anatomista francês J. P. Sucquet (18401870), preparador do Museu de Anatomia e Cavaleiro da Legião de Honra. Entre outras denúncias, de acordo com a notícia, os cadáveres embalsamados pelo primeiro eram descritos como decompostos e exalando um cheiro de putrefação sufocante. A acusação de uso do arsênico também foi imputada, destacando sua proibição na França pelo risco de dissimular crimes por envenenamento $^{22}$. Cabe ressaltar, entretanto, que a este tempo Gannal havia substituído o arsênico por uma solução aquosa composta de partes iguais de sulfato e cloreto de alumínio. Sucquet, por sua vez, utilizava o cloreto de zinco $^{23}$.

Um longo caminho foi percorrido antes que Jean-Nicolas Gannal tentasse tornar a técnica da conservação de cadáveres em um negócio lucrativo em larga escala a ponto de atrair médicos como Tavano a serem seus cessionários em países distantes, como o Brasil. Suas pesquisas partiram de trabalhos de gerações anteriores, como William Harvey (1578-1657), que por sua vez possibilitou ao holandês Frederick Ruysh (1665-1717) ter sido um dos primeiros a praticar o método de injeção na artéria femoral, embora com o objetivo de preservar peças para o estudo da anatomia e não como prática mortuária. Ruysh não revelou os segredos de seu método, mas há indícios de que, além da injeção na artéria femoral, ele fazia a abertura do corpo para remoção, lavagem e reintrodução das vísceras com uma solução preservadora ${ }^{24}$. Ao contrário de Ruysh, que não publicou seu trabalho, o médico escocês William Hunter (1718-1783) foi reconhecido como o inventor do sistema de injeção na artéria femoral para embalsamamento de cadáveres como prática mortuária. A técnica de Hunter era feita utilizando solução de terebintina e óleo de lavanda, além de retirada, tratamento e reintrodução das vísceras. O corpo deveria ser exumado após um período de quatro anos e receberia novo tratamento, caso ainda não estivesse $\operatorname{seco}^{25}$.

${ }^{20}$ De acordo com a medicina da época, a apoplexia cerebral consistia na congestão de sangue no cérebro. Dependendo do grau poderia variar de leve, causando uma simples vertigem, até fulminante, levando às vezes à morte súbita. Ver: CHERNOVIZ, Pedro Luiz Napoleão. Dicionário de Medicina Popular. Paris: A. Roger \& F. Chernoviz, 1890. V. 1, p. 199-200.

${ }^{21}$ Diário do Rio de Janeiro, RJ, edição 144, 16 e 17 de agosto 1860, p. 1.

22 Correio Mercantil, RJ, edição 105, 14 de abril 1860, p. 2 e "Um estudante de medicina legal. O cessionário do sistema Gannal", edição 231, 20 de agosto 1860, p.3.

${ }^{23}$ SUCQUET, J. P. Rapporte sur divers modes d'embaumement extrait du Bulletin de l'Académie de Médecine. Embaumement-Histoire de l'embaumements et des embaumeurs. Disponível em: <http//www.embaumement.com>. Acesso em: 15 de dezembro 2017.

${ }^{24}$ BARNS, Carl Lews. The art and science of embalming: descriptive and operative. Washington: Librarian of Congress, 1898. p. 223. Disponível em: <https://archive.org/details/artandscienceem00barngoog>.

${ }^{25}$ NUNNAMAKER, Albert John; DHONAU, Charles. Anatomy and embalming: a treatise on the science and art of embalming, the latest and most successful methods of treatment and the general anatomy relating to this subject. Ohio: The Embalming Book Company, 1913. p. 21 e 22. Disponível em: $<$ https://archive.org/details/anatomyembalming00nunn $>$. 
Antes da invenção de Jean-Nicolas Gannal, os embalsamamentos eram realizados, na França, com base nos ensinamentos contidos na obra de Pierre Dionis (1643-1718) e na antropotomia de Pierre Tarin (1725? -1761), conforme atestou o médico François Ribes pére (1770$1845)^{26}$. Tais operações, que talhavam e dividiam o corpo humano, causavam a Gannal um verdadeiro horror, sendo, em sua opinião, "mais cruel para o coração que a destruição e a dissolução natural das partes". O fato é que ele se debruçou, de início, sobre o processo de preservação de peças anatômicas, a este se dedicando por nove anos, a partir de 1826. Sua principal inovação foi a utilização de uma injeção composta de soluções de acetato e cloreto de alumínio por meio de aplicação nas artérias carótidas. A mesma técnica passou a ser aplicada nas práticas mortuárias, sendo combinada às lavagens aromáticas para permitir que se evitasse a mutilação do corpo por meio da retirada das vísceras ${ }^{27}$.

O cessionário José Tavano assim descreveu a referida técnica de embalsamamento:

Coberto o corpo, é colocado sobre uma mesa; e, mediante uma incisão feita no pescoço, busca-se a carótida, artéria pela qual se injeta o líquido conservador. Isto feito e sem se lhe descobrir parte alguma, envolve-se inteiramente o corpo em toalhas de flanela ou seda, atadas com bandas do mesmo tecido; após o que, veste-se a pessoa falecida segundo sua família deseja.

Desta maneira, tiram-se os linhos manchados pelas dejecções, como praticam as religiosas nos enterros, apertando-o com estofos impregnados em essências lançadas no caixão.

As conservações ditas temporárias e consistentes em mera injeção bastam para conservar os corpos durante alguns meses, sem, todavia, darem conservações indefinitas, como algumas pessoas imaginam. ${ }^{28}$

Quanto à trajetória de vida de Gannal, há relatos de que aos 14 anos começou a trabalhar em uma farmácia, quando aprendeu a manipular substâncias químicas. Alistou-se no exército francês e atuou nos hospitais militares, acompanhando as forças bélicas de Napoleão nas campanhas da Alemanha e da Rússia. Após a batalha de Waterloo, retornou a Paris e se vinculou à Escola Politécnica como preparador químico. Dedicou-se a diversas atividades, como o desenvolvimento de um método para a refinação de bórax ${ }^{29}$, resultando em grande queda no preço final deste produto; trabalhou em um novo processo para derretimento e endurecimento de sebo, técnica que viabilizou a posterior fabricação de velas de cera; atuou na feitura de cola e gelatina, de sucos açucarados e acidulados ${ }^{30}$.

${ }^{26}$ RIBES, FRANÇOIS. Histoire de l'ouverture et de l'embaumement du corps de Louis XVIII, fondateur de l'Académie royale de médecine / par F. Ribes père, médecin ordinaire de l'Hôtel royal des Invalides. PARIS: Impr. de Plassan, 1834. Disponível em: <http://gallica.bnf.fr/ark:/12148/bpt6k6128757p>. Acesso em: 11 de maio de 2018.

${ }^{27}$ GANNAL, Jean-Nicolas. Histoire des embaumemens et de la préparation des pièces d'anatomie normale, d'anatomie pathologique et d'bistoire naturelle, suivie de procédés nouveaux, par J.-N. Gannal. Paris: Ferra, 1838. Disponível em: <http://gallica.bnf.fr/ark:/12148/bpt6k96183929>. Acesso em: 11 de maio de 2018.

28 TAVANO, José.” Notícia acerca dos embalsamamentos". Correio Mercantil, RJ, edição 106, 17 de abril 1860. (Continuado do número 103).

${ }^{29}$ De acordo com Chernoviz, o bórax também era conhecido como sub-borato de soda, sendo empregado nas artes e na medicina, mais especificamente em gargarejo para o tratamento de aftas. Ver: CHERNOVIZ, Pedro Luiz Napoleão. Op. cit., vol. I, p. 347.

30 TOULOU $\underline{Z E}$, M. Eug. "Variétés. Les Gannal et les embaumememts aux siècles passes et dans les temps modernes". Gazette des hopitaux civils et militaires, Paris, 103,1905. p. 1229-1231. Disponível em: <

BOMBOY, E. "Le embaumeur Jean-Nicolas Gannal". Le Progrés Medical, Paris, 1936, Supplèment Illustré, p. 92-95.

Disponíveis em biuSanté Bibliothèque Numérique Medic@ 
Por não ser médico, não foram poucas as dificuldades enfrentadas pelo químico francês, segundo lamentou-se certa vez, quando já tinha 30 anos de experiência na prática da referida arte, denunciando os problemas pelos quais estava passando, principalmente as objeções feitas ao seu método de embalsamamento por uma comissão constituída, em meados da década de 1840, pela Academia Real de Medicina. Gannal, que obteve seu brevê de invenção para o líquido de embalsamamento em 1845, defendeu-se da acusação de que usava arsênico e revelou ser alvo de críticas e agressões de seus adversários, com destaque para o já citado anatomista J. P. Sucquet, que o teria plagiado ${ }^{31}$. Da mesma forma que os egípcios praticavam o embalsamamento impulsionados por sentimentos de natureza religiosa, o químico francês apelou para a ideia de que estes eram uma expressão da religiosidade, testemunhando os sentimentos afetuosos, os lamentos e o reconhecimento da família e dos amigos. Discurso semelhante fez Tavano, ao defender a conservação dos despojos como uma forma de respeito aos mortos, além de tornar a separação menos dolorosa por parte da pessoa enlutada, pois "sabe que pode vê-lo, conhecê-lo, tocá-lo e até abraçá-lo, pois só lhe falta o divino sopro que se exalou com o último suspiro"32.

Para Gannal, embalsamamento era o mesmo que "procedimento contra a corrupção dos corpos mortos" 33 . Um dicionário francês da segunda metade do século XIX assim definiu a referida técnica: "Dá-se este nome à operação que tem por objeto obter a conservação artificial dos cadáveres". A mesma publicação afirma ainda o seguinte: "que a ideia de evitar a decomposição do corpo remonta aos egípcios; os gregos e romanos pouco o praticaram; a arte começou a se desenvolver na Europa a partir do século XVI"; e, finalmente, o costume desapareceria quando a desejada cremação se tornasse obrigatória. Ainda de acordo com este dicionário, o método utilizado por Gannal resultou da descoberta de um composto líquido contendo sulfato de alumínio, ácido arsênico e água destilada ${ }^{34}$. Importante notar que o químico francês sempre negou que usasse arsênico em suas formulações, substância cuja venda foi proibida na França em 1846, tanto em embalsamamentos quanto em inseticidas e outras atividades ${ }^{35}$.

Em meio às denúncias expostas no Correio Mercantil de que o sistema Gannal seria uma falácia, as quais agitaram também a França, Tavano viria a ser chamado para embalsamar um cadáver que já estava em decomposição, pois falecera há mais de 24 horas. Tratava-se de Francisco Mauker, um comerciante que viveu durante o século XIX na capital do Império, vendendo carruagens novas e usadas ${ }^{36}$. Era francês e morreu viúvo aos 40 anos de idade, em 21 de setembro de 1860, vítima de hepato enterite ${ }^{37}$, sendo sepultado em 25 de setembro de 1860, ou seja, quatro dias após sua morte ${ }^{38}$. A um amigo chamado Salvador Gonçalves da Cunha Bastos coube a iniciativa de providenciar a concretização de seu último desejo, qual seja, o de ter seu corpo

${ }^{31}$ GANNAL, Jean-Nicolas. Avis aux familles sur le mode d'embaumement de M. Gannal. Paris: Le Normant, 1846. Disponível em: <http://gallica.bnf.fr/ark:/12148/bpt6k9618464b>. Acesso em: 11 de maio de 2018.

32 TAVANO, José. "Notícia acerca de embalsamamentos". Correio Mercantil, RJ, edição103, 4 de abril 1860, p. 3.

33 GANNAL, 1846, op. cit. [n.p.].

${ }^{34}$ LABARTHE, Paul. Dictionnaire Populaire de Médecine Usuelle. Paris: C. Marpon et E. Flammarion, 1887. Tomo 1, p. 699.

${ }^{35}$ Sobre a citada regulação francesa acerca da venda de substâncias tóxicas por farmacêticos, ver: $\mathrm{N}^{\circ} 440$. 29 de outubro -6 de novembro de 1846. Ordonnance du Roi portant règlement sur la vente des substances vénéneuses (IX, Bull. MCCCXXXVIII, nº13.098). Titre II: De la vente des substances vénéneuses par les pharmaciens. In: FRANCE. Bulletin des lois et ordonnances publiées depuis la Révolution de juillet 1830. Paris: Imprimerie et librairie administratives de Paul Dupont, 1846. Tomo 5, n.440. p. 140. Disponível em: <http://gallica.bnf.fr/ark:/12148/bpt6k6456874g>. Acesso em: 11 de maio de 2018.

36 "Carruagens ricas". Jornal do Comércio, RJ, edição 141, 22 de maio 1860, p. 3 e "Fábrica de seges". Correio Mercantil, RJ, edição 25, 25 de janeiro 1860, p. 3.

37 Conforme Dictionaire Abregé des Sciences Médicales (Paris: Panckoucke Editeur, 1822. Tomo VI, pp.477514), denominava-se enterite uma inflamação dos intestinos. No caso da bepato enterite, citada no texto, tudo indica que o paciente sofria também de um problema no fígado. Disponível em: $<$ https://archive.org/stream/BIUSante_35573x06>. Acesso em: 11 de maio de 2018.

38 "Obituário". Correio Mercantil, RJ, edição 268, 26 de setembro 1860, p. 1. 
embalsamado para a posteridade. O relato deste amigo foi publicado em um jornal da época, trazendo uma breve reconstituição do que se passou nos dias entre a morte e o enterramento definitivo do comerciante. Passadas mais de 24 horas da morte de Francisco Mauker, durante a leitura do testamento, Cunha Bastos soube de seu último desejo e recorreu ao médico José Tavano, que aceitou fazer o embalsamamento "paralisando a decomposição imediatamente depois da operação"39.

Decorridos dois anos da morte de Mauker, em janeiro de 1862, o nome do falecido comerciante passou a aparecer na imprensa carioca, em uma troca de artigos publicados no Jornal do Comércio e no Correio Mercantil. Os textos eram de autoria do médico que o embalsamou, José Tavano, e de seu detrator, que se manteve anônimo sob o pseudônimo $A$ alma de Mauker. Tratava-se, provavelmente, de um concorrente do médico português na arte do embalsamamento, que, em tom irônico, levantou a dúvida de que Tavano de fato utilizasse os genuínos líquidos preservadores de Gannal e de que fosse verdadeiramente iniciado nos verdadeiros mistérios e segredos dessa prática. Para justificar suas acusações, mencionou diversos cadáveres que haviam se corrompido após serem por ele embalsamados. Um deles teria sido o corpo de uma criança depositado em um gabinete na Escola de Medicina, cuja chave da porta permanecia em poder de Tavano. Ao exalar um cheiro infecto, a diretoria do local ordenou que sem perda de tempo fosse restituído à terra esse cadáver que "nunca deveria ter sido profanado pela seringa do embalsamador", denunciou o detrator ${ }^{40}$.

Com relação ao embalsamamento de Francisco Mauker, o autor anônimo do referido artigo forneceu mais informações. Após o embalsamamento, seu corpo teria sido depositado provisoriamente na capela do cemitério de São João Batista ${ }^{41}$, em 23 de setembro de 1860, porque ainda não estariam prontos os caixões de chumbo e de madeira onde o cadáver deveria ser depositado. 'No dia seguinte, a 'infecção' era notável no recinto da capela e se fazia sentir até mesmo no escritório vizinho". Zelosa pela saúde de seus empregados, a administração chamou o doutor Tavano para concluir seu trabalho e remover o corpo de Mauker, que se achava "corrupto". No dia seguinte, em 25 de setembro, o médico português esteve na capela do cemitério e solicitou o uso do local por mais algumas horas. No mesmo dia à tarde, ali compareceram o construtor dos caixões e um emissário do médico. Na ocasião, lançaram sobre o corpo uma grande porção de líquidos aromáticos e o encerraram no caixão metálico hermeticamente fechado e soldado ${ }^{42}$.

O autor anônimo desse mesmo artigo levantou duas hipóteses para o suposto fracasso dos embalsamamentos de Tavano, no Rio de Janeiro. Uma delas seria de que o líquido utilizado pelo médico era falsificado. Argumentou ser possível que Gannal vendesse seus líquidos adulterados em tonéis ou garrafões para evitar a descoberta da verdadeira composição destes, o que poderia ser feito por uma simples análise. Outra hipótese consistia no fato de que os líquidos, caso fossem os legítimos provenientes da França, não seriam propícios para o clima tropical do Brasil, onde a "fermentação pútedra" ocorreria com grande rapidez. Citando, por fim, a exumação do cadáver de um menino chamado Francisco, embalsamado por Tavano e encontrado na mais completa putrefação, propôs a Tavano exumar todos os corpos por ele embalsamados, inclusive o de Mauker, assim o desafiando:

39 BASTOS, Salvador Gonçalves da Cunha. "Publicações a pedido: agradecimento". Correio Mercantil, RJ, edição 267, 25 de setembro 1860, p. 3.

40 "Publicações a pedido: a alma de Mauker: os embalsamamentos e o sr. Dr. Tavano, cessionário do processo de Gannal". Correio Mercantil, RJ, edição 10, 10 de janeiro 1862, p. 2.

41 O cemitério de São João Batista, na Freguesia da Lagoa, foi inaugurado em 1852 e era público, ou seja, destinado às pessoas pobres. O governo provisório da República implantou a lei de secularização dos cemitérios somente em 1891. A propósito, ver: RODRIGUES, Cláudia. Nas fronteiras do além: a secularização da morte no Rio de Janeiro (séculos XVIII e XIX). Rio de Janeiro: Arquivo Nacional, 2005.

42 "Publicações a pedido (...)". Loc. cit., p.2. 
Será pelo receio de qualquer verificação ulterior que o ilustre cessionário ora proscreve totalmente qualquer comunicação com o mundo exterior, ainda mesmo através de um vidro espesso, que em nada prejudicaria aliás o êxito de sua operação, como praticou com o cadáver de Mauker, ora dispõe apenas de um estreito óculo, através do qual qualquer reconhecimento satisfatório e completo se torna necessariamente impossível?... E que vantagem enxergar-se pois na conservação indefinida de um corpo, que não mais poderá ser convenientemente visitado, nem receber sequer um olhar saudoso? 43

Divulgada na mesma edição e página do Correio Mercantil em que o artigo foi publicado, uma notícia intitulada Exumação ajuda a entender o caso do menino Francisco. Na presença de familiares e professores da Faculdade de Medicina, o corpo da criança foi exumado no cemitério de São Francisco de Paula. "Teve, pois o pobre pai o desapontamento de encontrar apenas, em lugar da imagem de um filho chorado, um montão de putrilagem amorfa e de cheiro infecto". Acusando Tavano, o autor anônimo do texto informou que o embalsamador foi convidado a comparecer à exumação do cadáver do menino, mas se negou a ir $^{44}$. Poucos dias depois, o médico português veio a público, no Jornal do Comércio, para se defender de todas as acusações. Além de garantir ter provas documentais para comprovar ser cessionário de Gannal, esclareceu as seguintes questões:

Se esses líquidos são ou não os mais próprios, mesmo neste clima, nos polos ou no equador, para garantir a conservação dos cadáveres, prova-o a experiência, os fatos, a realidade. Tenho no meu escritório, membros do corpo humano embalsamados há mais de ano e se acham em perfeitíssimo estado de conservação. Chamaria também em meu apoio não menor autoridade que a de um ilustre professor a quem convidei para a minha primeira experiência de embalsamamento nesta corte. Essa experiência foi feita na escola de medicina no cadáver de uma criança; a chave do anfiteatro onde ficara o cadáver se conservou sempre em poder do porteiro da escola e não comigo, como falsamente se alega. Daqui resultou que o cadáver embalsamado pode ser visitado por muitos médicos (...). 45

Com relação às acusações feitas sobre o embalsamamento de Mauker, Tavano reproduziu na íntegra o depoimento do amigo do falecido, Salvador Gonçalves da Cunha Bastos, que esteve presente ao sepultamento definitivo, quando o cadáver foi colocado em caixão de chumbo: "Encontrei o cadáver em perfeito estado de conservação, o que foi presenciado por diversas pessoas que assistiram à exumação", escreveu o amigo. Ao responder à acusação de que o cadáver do menino Francisco houvesse sido mal embalsamado, imputou outra ainda mais grave, qual seja, a de que o túmulo em que jazia o corpo da criança já havia sido aberto anteriormente por outra pessoa interessada em prejudicá-lo, ou seja, “as coisas já estavam preparadas para o resultado que se desejava”. Sobre o episódio, disse ter recebido dois convites para uma segunda exumação: o primeiro, pedindo que marcasse dia e hora para a exumação e o segundo, no dia seguinte, estabelecendo que o ato se daria em poucas horas. Não aceitara o convite, alegando compromissos de trabalho e porque sabia daquela "primeira e misteriosa exumação". Em sua defesa, Tavano ainda relatou, mediante ordem do Marquês de Abrantes, Miguel Calmon du Pin e Almeida (1796-

43 "Publicações a pedido (...)". Loc. cit., p. 2.

44 "Exumação". Correio Mercantil, RJ, edição 10, 10 de janeiro 1862, p. 2.

45 “O Dr. J. Tavano ao público". Jornal do Comércio, RJ, edição 17, 17 de janeiro1862, p. 1. 
1865), ter recentemente visitado diversos cadáveres por ele embalsamados e encontrou todos em perfeito estado de conservação ${ }^{46}$. Tudo indica que Tavano fez questão de informar que obteve autorização para não ser acusado de ter violado nenhuma sepultura, o que era crime passível de multa e prisão ${ }^{47}$. Já a referência ao Marquês de Abrantes se deu porque este era então provedor da Santa Casa e os cemitérios públicos do Rio de Janeiro estavam a cargo da administração da Santa Casa de Misericórdia ${ }^{48}$.

A troca de artigos deu-se em 1862, ou seja, no período em que ocorreu grande difusão de embalsamentos nos EUA por causa da guerra civil (1861-1865). O objetivo era possibilitar o translado dos combatentes, permitindo que fossem enterrados nas cidades em que viviam seus familiares. Com o crescimento da demanda por funerais caros, houve a procura por melhores meios de preservação do corpo, segundo dois autores do final do século XIX, Eliab Myers e F. A. Sullivan. Naquela época, o período do luto anterior ao enterro geralmente tinha a duração de dois a quatro dias e, em caso de necessidade de envio do corpo para locais distantes, poderia demorar meses. Antes da introdução do embalsamento nos EUA, o agente funerário ou quem quer que assumisse o controle do funeral geralmente tinha que lidar com cadáveres em terrível estado de putrefação, em consequência da dificuldade do transporte com gelo. Com o tempo, o embalsamento passou a ser praticado por dois motivos: questões de preservação e sanitárias, sendo esta última uma razão secundária. "Podem haver outras razões menores, mas estas são as principais", segundo os citados autores norte-americanos ${ }^{49}$. Entre os motivos menores mencionados, possivelmente estaria o embalsamamento por motivos sentimentais, como o do menino Francisco, ou por desejo pessoal, a exemplo de Mauker.

As motivações que levaram pessoas comuns a desejarem ser embalsamadas no século XIX fazem sentido diante das considerações de Edgar Morin, um dos primeiros autores a refletir sobre a morte. Publicada em 1951, sua obra foi muito anterior ao período em que a história das mentalidades passou a dominar a história social no âmbito dos Annales, quando os comportamentos diante da morte começaram a ser tratados como objetos de estudo ${ }^{50}$. Assim, o pioneirismo de Philippe Ariès torna-se, de certo modo, duvidoso. Ao analisar o fenômeno em sua dimensão bioantropológica, Morin refletiu sobre as atitudes do homem diante da morte como algo que o distingue dos outros seres vivos. Quanto ao sentimento de dor provocado pela morte de entes queridos manifestados no luto, apontou o "horror da decomposição do cadáver" como o mais forte. Diante da "perda da individualidade" da pessoa amada, esse sentimento seria a razão de diversas práticas funerárias às quais o ser humano tem recorrido com o passar dos tempos, tais como o embalsamamento, a cremação e o transporte do corpo para outro lugar, entre outras práticas ${ }^{51}$.

46 “O Dr. J. Tavano ao público". Loc. cit, p. 2.

47 De acordo com o capítulo II, art. 68 do Decreto no1.557 de 17/02/1855. Ver: BRASIL. Decreto ${ }^{\circ}$ 1.557, de 17 de Fevereiro de 1855. Aprova o novo Regulamento para os Cemitérios públicos e particulares da Cidade do Rio de Janeiro, serviço dos enterros e taxas funerárias. In: Coleção de Leis do Império do Brasil. Rio de Janeiro, 1855, p. 93, v. 1, pt. II (publicação original). Disponível em: < http://www2.camara.leg.br/legin/fed/decret/1824-1899/decreto-1557-17-fevereiro-1855-558427-publicacaooriginal79673-pe.html>. Acesso em: 11 de maio de 2018.

${ }^{48}$ BRASIL. MINISTÉRIO DO IMPÉRIO. Relatório apresentado à Assembleia Geral Legislativa na Segunda Sessão da Nona Legislatura pelo Ministro e Secretário de Estado dos Negócios do Império Luiz Pedreira do Couto Ferraz: Rio de Janeiro: Typographia do Diário, de A\&L Navarro, 1854. p. 11. Disponível em: <http://memoria.bn.br/pdf/720968/per720968_1853_00001.pdf>. Acesso em: 11 de maio de 2018.

49 MYERS, Eliab; SULLIVAN, Francis A. The champion text book on embalming. Springfield, Ohio: Champion Chemical Co, 1897. p. 113. Disponível em: <https://archive.org/details/championtextbook00myer>. Acesso em: 11 de maio de 2018.

${ }^{50}$ ARIÈS, Philippe. História da morte no Ocidente: da Idade Média aos nossos dias. Tradução de Priscila Viana de Siqueira. Rio de Janeiro: Nova Fronteira, 2017.

${ }^{51}$ MORIN, Edgar. O bomem e a morte. Tradução de Cleone Augusto Rodrigues. Rio de Janeiro: Imago, 1997. pp. 28-29; 33. 
Como afirmou o anatomista Vasseur, o embalsamamento era uma eventualidade tão rara que poderia sequer aparecer na vida de um médico. É possível que a pequena quantidade de clientes em potencial tenha contribuído para acirrar as disputas travadas tanto entre os embalsamadores na Europa do século XIX, como ocorreu com Gannal e Sucquet, quanto no Brasil, com Tavano e seu eventual concorrente. Para o químico francês, que teve como sucessores seus filhos Félix e Adolphe (1826-?), os embalsamamentos representavam uma atividade lucrativa, pois seus líquidos eram vendidos para cessionários localizados no interior da França e em outras regiões do mundo ocidental. Cabe lembrar que os irmãos se dedicaram, também, à conservação de carnes e legumes.

Um problema interessante que apareceu na troca de farpas que permeia os artigos assinados pelo médico José Tavano e seu inimigo anônimo foi a opção pelo embalsamamento feito com a intenção de preservar o cadáver para a posteridade por questões sentimentais. É possível que os familiares poderiam optar por essa técnica não apenas para translado ou para prolongar a duração dos funerais de pessoas ilustres ${ }^{52}$. Esse parece ter sido o caso do menino Francisco, exumado na presença do pai no cemitério de São Francisco de Paula. Ao se deparar com a decepção do progenitor durante a exumação do cadáver do filho embalsamado e que se encontrava em decomposição, o detrator de Tavano, ao criticá-lo pela qualidade de seu serviço, afirmou: "E que vantagem enxergar-se (sic) pois na conservação indefinida de um corpo, que não mais poderá ser convenientemente visitado, nem receber sequer um olhar saudoso?"53.

Oportuno lembrar, ainda, as observações satíricas sobre os praticantes da arte de "empalhar" feitas, em 1839, pelo crítico, jornalista e novelista francês Alphonse Karr (1808-1890). Ciente de que os embalsamadores tinham o hábito de roubar os órgãos, afirmou com ironia: "talvez os revendam aos mortos que têm falta de algum" 54 . Completamos: estes sempre foram muitos...

\footnotetext{
52 Sobre o embalsamamento de pessoas ilustres, ver, por exemplo, o caso ocorrido com o general José de San Martin (1778-1850), cujo corpo foi transladado da França para a Argentina. Ver: PODGORNY, Irina. Las momias de la patria: entre el culto laico, la historia de la química y la higiene pública. In: L'Ordinaire des Amériques. Toulouse, n. 212, 2010 [publicado em 1 de novembro de 2015], pp. 53-74. Disponível em: <http://journals.openedition.org/orda/2487>. Acesso em: 11 de maio de 2018.

53 "Publicações a pedido (...)". Loc. cit., p. 2.

${ }^{54}$ KARR, Alphonse. Les guêpes. Paris: Lange Lévy, 1841. p. 44.
} 